\title{
Assessment of the MSF triage system, separating patients into different wards pending Ebola virus laboratory confirmation, Kailahun, Sierra Leone, July to September 2014
}

F Vogt $^{1}$, G Fitzpatrick ${ }^{2}$, G Patten ${ }^{3}$, R van den Bergh ${ }^{1}$, K Stinson ${ }^{3}$, L Pandolfi 4 , J Squire ${ }^{5}$, T Decroo ${ }^{1}$, H Declerck ${ }^{1}$, M Van Herp ${ }^{1}$

1. Doctors Without Borders / Médecins Sans Frontières, Brussels, Belgium

2. Doctors Without Borders / Médecins Sans Frontières, Dublin, Ireland

3. Doctors Without Borders / Médecins Sans Frontières, Cape Town, South Africa

4. Doctors Without Borders / Médecins Sans Frontières, Amsterdam, Netherlands

5. Ministry of Health and Sanitation, Kailahun, Sierra Leone

Correspondence: Florian Vogt (florianvogt@hotmail.com)

Vogt F, Fitzpatrick G, Patten G, van den Bergh R, Stinson K, Pandolfi L, Squire J, Decroo T, Declerck H, Van Herp M. Assessment of the MSF triage system, separating patients into different wards pending Ebola virus laboratory confirmation, Kailahun, Sierra Leone, July to September 2014. Euro Surveill. $2015 ; 20(50)$ :pii=30097.

DOI: http://dx.doi.org/10.2807/1560-7917.ES.2015.20.50.30097

Article submitted on og April 2015 / accepted on 17 December 2015 / published on 17 December 2015

Prevention of nosocomial Ebola virus (EBOV) infection among patients admitted to an Ebola management centre (EMC) is paramount. Current Médecins Sans Frontières (MSF) guidelines recommend classifying admitted patients at triage into suspect and highlysuspect categories pending laboratory confirmation. We investigated the performance of the MSF triage system to separate patients with subsequent EBOVpositive laboratory test (true-positive admissions) from patients who were initially admitted on clinical grounds but subsequently tested EBOV-negative (false-positive admissions). We calculated standard diagnostic test statistics for triage allocation into suspect or highly-suspect wards (index test) and subsequent positive or negative laboratory results (reference test) among 433 patients admitted into the MSF EMC Kailahun, Sierra Leone, between 1 July and 30 September 2014. 254 (59\%) of admissions were classified as highly-suspect, the remaining 179 (41\%) as suspect. 276 (64\%) were true-positive admissions, leaving 157 (36.3\%) false-positive admissions exposed to the risk of nosocomial EBOV infection. The positive predictive value for receiving a positive laboratory result after being allocated to the highly-suspect ward was $76 \%$. The corresponding negative predictive value was $54 \%$. Sensitivity and specificity were $70 \%$ and $61 \%$, respectively. Results for accurate patient classification were unconvincing. The current triage system should be changed. Whenever possible, patients should be accommodated in single compartments pending laboratory confirmation. Furthermore, the initial triage step on whether or not to admit a patient in the first place must be improved. What is ultimately needed is a point-of-care EBOV diagnostic test that is reliable, accurate, robust, mobile, affordable, easy to use outside strict biosafety protocols, providing results with quick turnaround time.

\section{Introduction}

The current Ebola virus disease (EVD) epidemic in West Africa is unprecedented in history [1]. After the outbreak was officially confirmed in Guéckedou, Guinea, on 23 March 2014 [2] and subsequently developed into a major epidemic with widespread infection in most parts of Guinea, Liberia, Sierra Leone [3], the World Health Organization (WHO) declared the situation a 'Public Health Emergency of International Concern' on 8 August 2014 [4]. By that time, Doctors Without Borders / Médecins Sans Frontières (MSF) was already running six Ebola management centres (EMC) in the these mostaffected countries - including one in Kailahun district, Sierra Leone [5].

Ebola virus (EBOV) transmission occurs between humans through contact with body fluids from persons diseased with or who died from EVD [6]. Typical symptoms are sudden onset of fever and a variety of nonspecific symptoms such as fatigue, headache, myalgia/ arthralgia or nausea within an incubation period of two to 21 days $[7,8]$. Infectiousness succeeds onset of clinical symptoms and increases with symptom severity [9]. While the reproductive number of Ebola virus (EBOV) is considerably smaller than that of other more common infectious agents, it is highly contagious in case of direct physical contact $[10,11]$. Infection is confirmed by laboratory testing, most often by quantitative reversetranscriptase PCR (qRT-PCR) from venous whole blood samples [12]. 


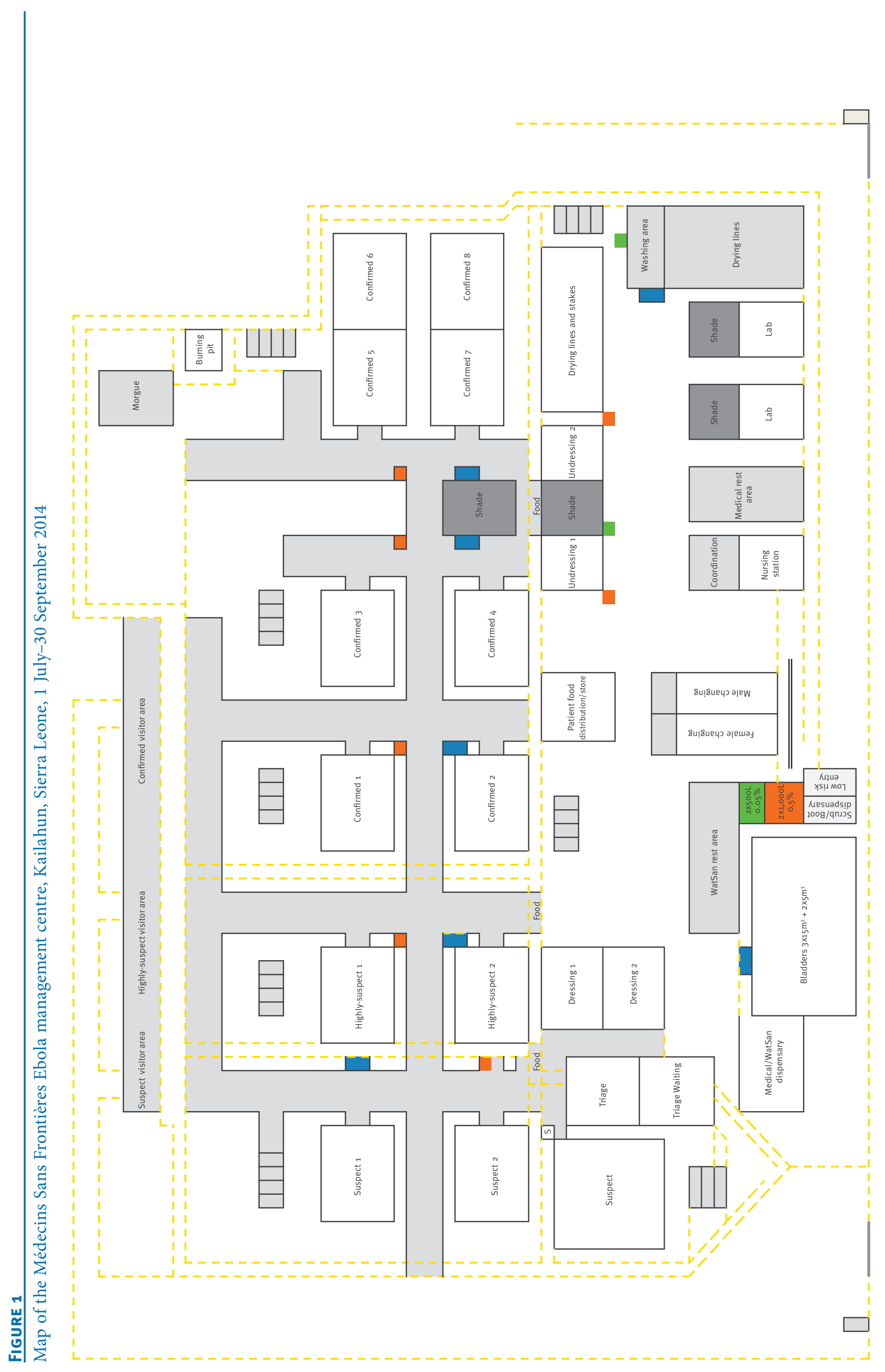

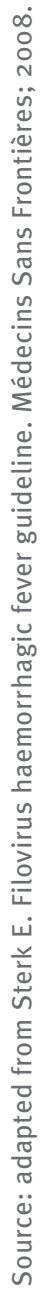




\section{FIGURE 2}

Médecins Sans Frontières triage algorithm for separating admitted patients into suspect or highly-suspect wards as used at the Ebola management centre Kailahun, Sierra Leone, 1 July-30 September 2014

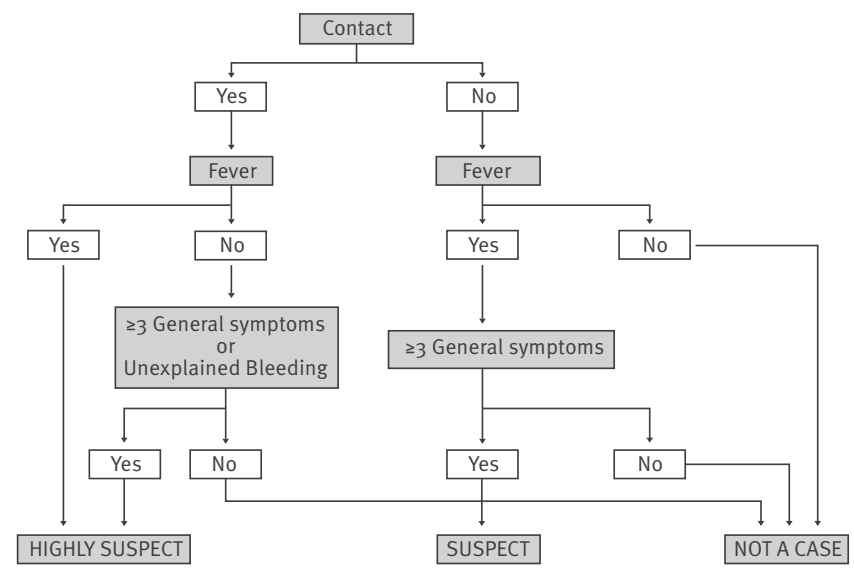

Source: adapted from Sterk E. Filovirus Haemorrhagic Fever Guideline. Médecins Sans Frontières; 2008.

In the absence of curative treatment, quick and strict isolation of symptomatic persons in EMCs is the main intervention to prevent new infections [13,14]. Admission into an EMC depends on clinical and epidemiological criteria until EBOV infection status is laboratory confirmed. A number of case definitions have been developed for different settings of the current outbreak in West Africa [15-17]. Correct admission of EVD patients is difficult even for experienced medical staff due to non-specificity of symptoms and numerous other diseases with similar early symptoms prevalent in the region such as Lassa haemoragic fever or malaria.

Nosocomial infections among false-positive admissions between the time of admission and laboratory EBOV confirmation is a matter of great concern in the management of an EMC $[18,19]$. As a basic preventive measure, it is good practice to physically separate patients who are admitted based on clinical symptoms awaiting laboratory confirmation from patients who are laboratory-confirmed EVD cases [20]. Provided that laboratory capacity is available on site, this takes a few hours for patients with symptom onset more than 72 hours before admission. Although the PCR used for laboratory confirmation is highly sensitive, patients with symptom onset less than 72 hours before admission can test negative due to low viraemia during the early stage of disease [21-23]. These patients have to be re-tested at minimum 72 hours after symptom onset and are hence required to stay admitted for up to three days until their final infection status can be established [22].

To further reduce the risk of nosocomial EBOV transmission during this period among patients who turn out to be EBOV-negative, MSF classifies patients at admission into suspect and highly-suspect categories.
Suspect and highly-suspect patients are kept in separate wards until final laboratory results are available, after which they are either transferred to the confirmed ward or discharged as not a case. The classification into suspect and highly suspect is based on a standardised algorithm using the patient's reported contact history and a combination of clinical symptoms [24].

It is not known to what extent this triage system serves to differentiate between patients who subsequently test EBOV-positive by PCR (true-positive admissions) and patients subsequently testing EBOV-negative (false-positive admissions). Such information is crucial to decide whether such a refined three-pronged triage process justifies the ressource-intensive maintenance of separate wards for suspect and highly-suspect patients in an EMC.

We aimed to investigate how well triage at admission into suspect and highly-suspect patients can separate between true-positive and false-positive admissions.

\section{Methods}

\section{Setting}

Kailahun district has an estimated population of 360,000 and is located in the Eastern Province of Sierra Leone bordering Guinea and Liberia [25]. Its capital and largest city is the town of Kailahun, located ca $80 \mathrm{~km}$ from Guéckedou, Guinea where the first EVD case in West Africa was recorded on 25 March 2014 [26]. Kailahun district has been the epicentre since the beginning of the EVD epidemic in Sierra Leone with intense transmission occurring at all levels of society [27].

MSF activities in Kailahun started in June 2014 with the erection of an EMC [5]. Initial bed capacity was 50 and increased to 80 in July due to high case load. The management of this particular EMC has already been described in detail elsewhere [28]. Its setup follows the standard MSF EMC layout with separate wards for suspect, highly-suspect, and confirmed cases (Figure 1).

\section{Admission, triage and laboratory testing}

Records from all patients who fulfilled the MSF EVD case definition criteria for admission and were hence admitted into the MSF EMC in Kailahun between 1 July and 30 September 2014 were used in this analysis. During the time of analysis the triage system in the MSF EMC in Kailahun was three-pronged with suspect, highly suspect and not a case as outcomes as per MSF guidelines [24]. All patients fulfilling the criteria for either suspect, highly suspect, or confirmed EVD case were admitted (Table 1 and Table 2). Patients who did not qualify for admission were cleared to leave the EMC as soon as possible. No detailed medical or epidemiological information was kept from these patients due to high work load. 
TABLE 1

Triage criteria at Médecins Sans Frontières Ebola management centre, Kailahun, Sierra Leone, 1 July-30 September 2014

\begin{tabular}{|l|c|c|c|c|c|}
\hline \multirow{2}{*}{ Criteria $^{\mathrm{a}}$} & \multicolumn{5}{|c|}{ Sets of criteria to be fulfilled for different wards } \\
\cline { 2 - 6 } & Suspect & Highly suspect & Highly suspect & Highly suspect & Confirmed \\
\hline Positive contact history & - & $\mathrm{X}$ & $\mathrm{X}$ & $\mathrm{X}$ & - \\
\hline Fever & $\mathrm{X}$ & $\mathrm{X}$ & - & - & - \\
\hline$\geq 3$ General symptoms & $\mathrm{X}$ & - & $\mathrm{X}$ & - & - \\
\hline Unexplained bleeding & - & - & - & $\mathrm{X}$ & - \\
\hline Positive laboratory EBOV test result & $\mathrm{b}$ & - & - & - & $\mathrm{X}$ \\
\hline
\end{tabular}

EBOV: Ebola virus.

a See Table 2 for definitions.

bor referral patients.

Patients fulfilling the admission criteria were allocated into the suspect ward if they presented with fever (axillary temperature $\geq 37.5^{\circ} \mathrm{C}$ ) plus at least three of the following general symptoms: abdominal pain, diarrhoea, difficulties breathing, difficulties swallowing, general muscular or articular pain, headache, hiccups, intense fatigue, nausea/loss of appetite, or vomiting. Patient with a positive contact history plus fever; or with a positive contact history plus at least three general symptoms; or with a positive contact history plus unexplained bleeding, were allocated into the highlysuspect ward (Table 1 and Figure 2). Patients in the suspect and highly-suspect wards were not allowed to mingle, and toilets and hand washing points were separate for each ward.

A peripheral venous blood sample was drawn for PCR testing from all admitted patients and tested for presence of Zaire EBOV on qRT-PCR assays for RNAdependent RNA polymerase (L) and nucleoprotein (NP) target genes [29] using RNA Master Hydrolysis reagents on a Lightcycler Nano platform (Roche Diagnostics, Laval QC, Canada). Cycle threshold (CT) values below 40 were considered EBOV positive. Patients whose test returned positive were transferred into the confirmed ward. Patients with a negative PCR result were discharged immediately if their onset of symptoms was more than 72 hours prior. For patients with a negative result and symptom onset less than 72 hours prior, a second sample was drawn at least 72 hours after the reported time of symptom onset [22]. A field laboratory was operating on site, which was able to provide sameday results for samples taken during morning hours. However, since most admissions occurred during the afternoon and evening times, many admitted patients had to stay overnight in either the suspect or highlysuspect ward until a blood sample was taken and analysed the following day.

\section{Data source and analysis}

Demographic, epidemiological and clinical information of all admissions was routinely collected during triage in paper-based registers. From this, operationally relevant data were entered on a daily basis into the MS
Excel-based project database, which was used for this analysis: patient age (in years), sex (male, female), date of symptom onset, date of admission, triage ward allocation (suspect, highly suspect), laboratory test result (positive, negative and CT value from PCR testing at admission), treatment outcome (discharged as not a case, discharged cured, death, transferred out), and date of outcome.

Percentages and medians were calculated to describe patient characteristics at admission and during the course of treatment. Overall sensitivity, specificity, positive predictive value (PPV), negative predictive value (NPV), positive likelihood ratio (PLR) and negative likelihood ratio (NLR) were calculated for the triage decision into suspect or highly-suspect ward (index test) with laboratory PCR result as gold standard (reference test). PPVs and NPVs are dependent on the pre-test probability, with increasing PPV and decreasing NPV the higher the pre-test probability ceteri paribus [30]. In our situation, the pre-test probability for at the classification into suspect or highly suspect was defined by the overall proportion of true-positive admissions (patients with subsequent laboratory-confirmed positive test result) during the initial triage decision to admit or not to admit a patient. Therefore, PPV and NPV were also calculated for different weekly rates of true-positive admissions: equal or less than $50 \%, 51$ to $70 \%$, and more than $70 \%$. Software package STATA v.11 (Stata Corporation, Texas 77845, US) was used for the statistical analysis.

\section{Ethics}

This research fulfilled the MSF Ethics Review Board (Geneva, Switzerland) criteria for exemption from full ethics review. This study was conducted as part of a formal project agreement with the Government of Sierra Leone and approved by the health authorities of Kailahun district.

\section{Results}

Records from 433 patients admitted between 1 July and 30 September 2014 were included in the analysis. 244 (57\%) of these patients were male, median age was 28 
TABLE 2

Definitions of the admission and triage criteria at Médecins Sans Frontières Ebola management centre Kailahun, Sierra Leone, 1 July-30 September 2014

\begin{tabular}{|c|c|}
\hline Criteria & Definition \\
\hline Fever & $\begin{array}{l}\text { Sudden onset rise of axillary } \\
\text { temperature }>37.5^{\circ} \mathrm{C} \text {. }\end{array}$ \\
\hline \multirow{3}{*}{ Contact history } & $\begin{array}{l}\text { Sharing the same bed, household or meals, } \\
\text { or touching the same objects as a suspected, } \\
\text { probable or confirmed EVD case within the } \\
\text { last } 21 \text { days. }\end{array}$ \\
\hline & $\begin{array}{l}\text { Caring for a suspected, probable or } \\
\text { confirmed EVD case including touching body } \\
\text { fluids within the last } 21 \text { days. }\end{array}$ \\
\hline & $\begin{array}{l}\text { Participating in funeral practices with } \\
\text { direct contact of the corpse or objects used } \\
\text { during funeral of a suspected, probable or } \\
\text { confirmed EVD case within the last } 21 \text { days. }\end{array}$ \\
\hline \multirow{11}{*}{$\begin{array}{l}\text { General } \\
\text { symptoms }\end{array}$} & Headache \\
\hline & Vomiting \\
\hline & Nausea \\
\hline & Loss of appetite \\
\hline & Diarrhoea \\
\hline & Intense fatigue \\
\hline & Abdominal pain \\
\hline & General muscular or articular pain \\
\hline & Difficulties swallowing \\
\hline & Difficulties breathing \\
\hline & Hiccups \\
\hline
\end{tabular}

EVD: Ebola virus disease; EBOV: Ebola virus.

years (interquartile range (IQR): 19-40), and median duration between symptom onset and admission was four days (IQR: $2-7$ ) (Table 3A). The median duration of hospitalisation varied between one, four and 15 days for patients discharged as not a case, dead and cured, respectively (Table ${ }_{3} \mathrm{C}$ ). The case fatality ratio among laboratory-confirmed positive patients with available clinical outcome was 51\% (131/255). Sixteen patients died before their positive laboratory result became available. All of them had been allocated into the highly-suspect ward.

Of the 433 admitted patients, 254 (59\%) including 128 men and 126 women were triaged into the highly-suspect ward. The remaining 179 (41\%) admissions were considered suspect and comprised 116 men and 63 women. The vast majority of laboratory results were obtained at the same or the following day of admission (median: 1 day; IQR: 1-1).

Overall, 276 (64\%) of the admitted patients, including 136 men, had a subsequent positive laboratory result (true-positive admissions), leaving 157 (36\%) with subsequent negative laboratory result (false-positive admissions) exposed to the risk of nosocomial EBOV infection (Table 3B).
The PPV for receiving a subsequent positive laboratory test result after being allocated into the highly-suspect ward was $76 \%$ (95\% confidence interval (Cl): 70-81). The corresponding NPV, i.e. receiving a negative laboratory test result for the suspect ward, was 54\% (95\% $\mathrm{Cl}$ : 46-61). Sensitivity, specificity, PLR and NLP were $70 \%, 61 \%, 2 \%$ and less than $1 \%$, respectively (Table 4 ).

Among the 157 false-positive admissions, 96 (61\%) patients were allocated into the suspect ward and thus would from this triage system have been less exposed to infected patients. Of these 96 patients, 71 were male with median age of 25 years (IQR: $19-41$ ), and 25 were female with median age of 30 (IQR: 25-40). The test results were available on the same day of admission for 26 of these patients (27\%), the next day for 61 (63\%), two days after for six $(6 \%)$ and subsequent to three days for one ( $1 \%)$. Two patients ( $2 \%$ ) had missing values for the admission-to-result duration.

In contrast, 61 (39\%) false-positive admissions were allocated to the highly-suspect ward and were thus exposed to a potentially increased EBOV-contaminated surrounding in that ward while awaiting their laboratory test result. Of these 61 patients, 37 were male with median age of 31 years (IQR: 23.5-41), and 24 were female with median age of 26 years (IQR: 14-40). Most patients received their test results within the first day after admission, with 17 (28\%) getting results on the same day, 32 (52\%) the day after, six (10\%) on the second day, and four ( $7 \%$ ) subsequent to three days. Data were missing for two (3\%) regarding admissionto-result duration.

For patients admitted during weeks with a true-positive admission rate (i.e. pre-test probability) of $\leq 50 \%$, $51-70 \%$ and $>70 \%$, the PPVs were $60 \%, 72 \%$ and $85 \%$, respectively; the corresponding NPVs were 64\%, $45 \%$ and $46 \%$ (Table 5 ).

The overall median CT value of the admission PCR result was 24 (IQR: 21-32). There was no substantial difference in median CT values between patients triaged into the suspect and the highly-suspect ward: 25 (IQR: 25-32) and 24 (IQR: 21-32), respectively (p-value from Wilcoxon rank-sum test: 0.222 ).

\section{Discussion}

To our knowledge, this was the first assessment of a three-pronged triage system in an EMC with EVD patients being classified as suspect or highly suspect upon admission until laboratory confirmation.

The overall proportion of laboratory-confirmed EVD cases among admitted patients (true-positive admissions) at the EMC in Kailahun of $64 \%(n=276 / 433)$ was substantially higher than observed during a study in Conakry, Guinea, $(46 \%, n=37 / 80)$ [31] and similar to the six month average seen in Liberia ( $57 \%$, $n=2,941 / 5,132)$ [32]. However, this proportion alone is not an good indicator for triage quality since it is 


\section{TABLE 3}

Characteristics of patients admitted, triaged, and treated at the Médecins Sans Frontières Ebola management centre Kailahun, Sierra Leone, 1 July-30 September 2014 ( $\mathrm{n}=433)$

\begin{tabular}{|c|c|}
\hline Characteristics of patients & $N(\%)^{a}$ \\
\hline \multicolumn{2}{|l|}{ At admission } \\
\hline \multicolumn{2}{|l|}{ Sex } \\
\hline Male & $244(56)$ \\
\hline Female & $189(44)$ \\
\hline \multicolumn{2}{|l|}{ Age (years) } \\
\hline$<18$ & $93(21)$ \\
\hline $18-37$ & $206(48)$ \\
\hline $38-57$ & $100(23)$ \\
\hline$\geq 58$ & $27(6)$ \\
\hline Missing values & $7(2)$ \\
\hline Median (IQR; range) & $28(19-40 ; 1-80)$ \\
\hline \multicolumn{2}{|c|}{ Duration between symptom onset and admission (days) } \\
\hline $0-3$ & 169 (39) \\
\hline $4-7$ & $144(33)$ \\
\hline$>7$ & $68(16)$ \\
\hline Missing values & $52(12)$ \\
\hline Median (IQR; range) & $4(2-7 ; 0-27)$ \\
\hline \multicolumn{2}{|l|}{ During triage } \\
\hline \multicolumn{2}{|l|}{ Ward triage } \\
\hline Suspect & $179(41)$ \\
\hline Highly suspect & $254(59)$ \\
\hline \multicolumn{2}{|l|}{ Laboratory result } \\
\hline Negative & $157(36)$ \\
\hline Positive & $276(64)$ \\
\hline \multicolumn{2}{|c|}{ Duration between admission and laboratory result (days) } \\
\hline o & $70(16)$ \\
\hline 1 & $331(76)$ \\
\hline 2 & $18(4)$ \\
\hline 3 & $7(2)$ \\
\hline Missing values & $7(2)$ \\
\hline Median (IQR; range) & $1(1-1 ; 0-3)$ \\
\hline \multicolumn{2}{|l|}{ During treatment } \\
\hline \multicolumn{2}{|l|}{ Outcome } \\
\hline Not a case & $150(35)$ \\
\hline Cured & $124(29)$ \\
\hline Dead & $131(30)$ \\
\hline Transferred out & $4(1)$ \\
\hline Missing values & $24(6)$ \\
\hline \multicolumn{2}{|c|}{$\begin{array}{l}\text { Duration between admission and clinical outcome by type of } \\
\text { outcome }\end{array}$} \\
\hline Not a case (median, IQR, range) & $1(1-2 ; 0-7)$ \\
\hline Cured (median, IQR, range) & $15(10.5-19 ; 4-35)$ \\
\hline Dead (median, IQR, range) & $4(2-6 ; 0-31)$ \\
\hline $\begin{array}{l}\text { Transferred out (median, IQR, } \\
\text { range) }\end{array}$ & $-{ }^{b}$ \\
\hline Missing values & $21(5)$ \\
\hline Overall (median, IQR, range) & $4(2-10 ; 0-35)$ \\
\hline
\end{tabular}

IQR: interquartile range.

a Unless otherwise specified in row headings, percentages are shown in the column and are based on the column total for the subsection in question.

${ }^{\mathrm{b}}$ No observations.
TABLE 4

Overall test statistics for ward triage into suspect or highly suspect (index test) and Ebola virus positive or negative laboratory result (reference test), Médecins Sans Frontières Ebola management centre Kailahun, Sierra Leone, 1 July-30 September 2014 ( $n=433$ patients)

\begin{tabular}{|l|l|}
\hline Test statistics & $\%(95 \% \mathrm{Cl})$ \\
\hline Positive predictive value & $76.0(70.2-81.1)$ \\
\hline Negative predictive value & $53.6(46.0-61.1)$ \\
\hline Sensitivity & $69.9(64.1-75.3)$ \\
\hline Specificity & $61.1(53.1-68.8)$ \\
\hline Positive likelihood ratio & $1.8(1.5-2.2)$ \\
\hline Negative likelihood ratio & $0.5(0.4-0.6)$ \\
\hline
\end{tabular}

$\mathrm{Cl}$ : confidence interval; EBOV: Ebola virus.

Correct classifications: 193 among 254 highly-suspect patients (76\%) tested EBOV positive. 96 among 179 suspect patients (54\%) tested EBOV negative. False classification: 61 among 254 highly-suspect patients (24\%) tested EBOV negative. 83 among 179 suspect patients (46\%) tested EBOV positive.

subject to many factors unrelated to triage such as access and acceptability of the EMC, community perception of the nature and presentation of EVD, survival bias, EVD incidence in the source population, stage of the epidemic etc. Also, too rigid admission criteria are not desirable from a public health point of view since a true-positive admission ratio that approaches 100\% increases the likelihood that a substantial proportion of patients with EVD are not recognised at triage and sent back into their community infecting others.

Our findings reveal that $157(36 \%)$ of patients were admitted into the EMC Kailahun on false-positive clinical grounds. These patients were hence exposed to the risk of nosocomial EBOV infection in the EMC until they received their laboratory result. This risk was reduced in Kailahun thanks to a laboratory on site that was able to provide PCR results within one day or less for the vast majority of patients. However, this was not the case for many treatment settings during most parts of the current outbreak due to insufficient laboratory capacity, which led to substantial delays in EBOV status confirmation for many patients in other centres when caseloads were high [33].

The classification of true-positive admissions into the highly-suspect ward and of false-positive admissions into the suspect ward by the triage system applied in the EMC Kailahun showed mixed results. Considering that this was an additional triage step among patients who already fitted the EVD case definition criteria for admission, we expected a relatively high PPV (i.e. proportion of patients allocated into the highly-suspect ward who had a subsequent positive laboratory test) and a relatively lower NPV (i.e. proportion of patients allocated into the suspect ward that had a subsequent negative laboratory test). This was confirmed by an overall PPV of $76 \%$ and a corresponding overall NPV of $54 \%$ (Table 4 ). The ratio of the PLR (1.8) and NLR (0.5) 
Predictive values by weekly true-positive admission rate (pre-test probability) Médecins Sans Frontières Ebola management centre Kailahun, Sierra Leone, 1 July-30 September 2014 ( $\mathrm{n}=433$ patients)

\begin{tabular}{|l|c|c|c|c|}
\hline $\begin{array}{l}\text { Pre-test probability } \\
(\%)\end{array}$ & $\begin{array}{c}\text { True-positive admissions } \\
\text { classified as 'highly } \\
\text { suspect' }\end{array}$ & $\begin{array}{c}\text { True-negative admissions } \\
\text { classifications classified as } \\
\text { 'suspect' }\end{array}$ & $\begin{array}{c}\text { Positive predictive value } \\
\%(95 \% \mathrm{Cl})\end{array}$ & $\begin{array}{c}\text { Negative predictive value } \\
\%(95 \% \mathrm{Cl})\end{array}$ \\
\hline$\leq 50(\mathrm{n}=135)$ & $33 / 55$ & $51 / 80$ & $60.0(45.9-73.0)$ & $63.7(52.2-74.2)$ \\
\hline$>50-\leq 70(\mathrm{n}=121)$ & $52 / 72$ & $22 / 49$ & $72.2(60.4-82.1)$ & $44.9(30.7-59.8)$ \\
\hline$>70(\mathrm{n}=177)$ & $108 / 127$ & $23 / 50$ & $85.0(77.6-90.7)$ & $46.0(31.8-60.7)$ \\
\hline Overall & $193 / 254$ & $96 / 179$ & $76.0(70.2-81.1)$ & $53.6(46.0-61.1)$ \\
\hline
\end{tabular}

$\mathrm{Cl}$ : confidence interval.

was $3.6(95 \% \mathrm{Cl}: 2.4-5 \cdot 5)$, which suggests that correct ward allocation was very unlikely due to chance.

The proportion of patients in the suspect ward that turned out to be EBOV positive was 46\% (83/179). Under the assumption that this translated into a reduced risk of nosocomial infection compared with the overall EBOV positivity proportion of $64 \%(n=276 / 433)$, a total of $96(61 \%)$ among the false-positive admissions allocated into the suspect ward were exposed to a less risky environment thanks to this additional triage step. However, this in turn also implied that 61 (39\%) of the false-positive admissions allocated in the highlysuspect ward, where an elevated EBOV-positivity surrounding of $76 \%(n=193 / 254)$ was recorded, were exposed to a more risky environment. However, cycle threshold values, a proxy for viral load in blood, from admission test results did not differ between wards, suggesting that EBOV positive patients in either ward were equally infectious.

As to be expected, PPV and NPV varied reciprocally for different true-positive admission rates (i.e. pre-test probabilities). The PPV of ward allocation was $60 \%$ during weeks with true-positive admission rates of $50 \%$ or less, and increased substantially to $85 \%$ during weeks with more than $70 \%$ true-positive admission rates. The corresponding NPV decreased from $64 \%$ during weeks with low true-positive admission rates to $46 \%$ when weekly true-positive admission rates were above $70 \%$ (Table 5).

Triage of EVD patients is an immensely difficult yet crucial task, in particular at times when the caseload exceeds capacities as occurred in the EMC Kailahun during the time of analysis. It requires substantial experience, which is problematic to obtain with high staff turnover. MSF tried to address this problem by developing a clear and standardised triage algorithm for patient classification. Also, triage at the EMC Kailahun was always done in pairs of at least one national staff together with one international staff to overcome cultural and linguistic barriers as much as possible.

Physical barriers, however, remained. Any clinical assessment could only be done by distance of minimum two metres across a double fence. No additional diagnostic methods other than a thermometer could be used. Also, many EVD patients at admission showed signs of confusion or exhaustion, or were otherwise clinically too unwell to describe their symptoms or contact history in detail. Furthermore, patients were often scared to disclose behaviour that, due to intense health promotion activities, had become proscribed, such as body washing at funerals or physical contact with persons showing EVD symptoms. Also, due to the high caseload it was not always possible to assure privacy during triage. This might have further limited the quality of information provided by patients during the triage process.

Timely isolation is paramount in order to break chains of transmission during an EVD outbreak. The sooner an infected person gets isolated after symptom onset the smaller the chance of infecting others. In this study, the median time span between symptom onset and admission was four days (IQR: $2-7$ ). This delay was most likely a driving factor for the continuous transmission as observed in Kailahun district, and substantial efforts were made to reduce it. However, the earlier an infected person presents at the EMC, the less pronounced and specific are the symptoms, which in turn further complicates correct patient triage at admission.

The construction and maintenance of two separate wards for patients awaiting laboratory confirmation poses a substantial burden on the logistics, the water and sanitation, and the infection control team of an EMC. Duplicate infrastructure and more staff and supply are required. More entries into the high risk zone by healthcare workers are needed to assure adequate patient care in the separate wards, which increases the risk of EBOV exposure incidents for staff. Balancing these factors against the ambivalent findings of this analysis calls the justification of the three-pronged MSF triage system in its current form into question.

Ideally, admitted patients should be accommodated in single compartments before laboratory confirmation to minimise nosocomial EBOV transmission in an EMC. This, however, was not possible in Kailahun due to high case load at that time. Alternatively, instead of using a 
rather sophisticated algorithm requiring detailed contact and clinical information, a simplified classification into liquid producing patients (i.e. patients with bleeding, diarrhoea or vomiting) and non-liquid producing patients might be advisable. This would be easier to apply for healthcare workers and would make triage quicker, while focussing on the probability of transmitting EBOV infection among patients rather than on the probability of an individual patient testing EBOVpositive. However, such a triage system would warrant further research before being implemented.

This research was subject to a number of limitations. Most importantly, the actual incidence and prevention of nosocomial infections among patients could not be assessed. Thus it remains unclear whether awaiting laboratory confirmation in an EMC as a false-positive admission actually results in any nosocomial EBOV infections, and whether an environment of $46 \%$ EBOVpositivity as observed in the suspect ward indeed reduces such a risk compared with $76 \%$ EBOV-positivity as observed in the highly-suspect ward. During the first nine weeks of operations, we recorded 15 readmitted patients. Among these readmitted patients, nine tested positive. These were patients who were tested negative during a first admission in the EMC, were discharged, and tested positive when they were admitted a second time, within 21 days of their initial admission. In-depth case investigations revealed one or more other high-risk exposure events in the community for all of these patients [18]. Though the exact source of infection could not be established with certainty, the total absence of readmissions without communityrelated high-risk exposure events in the 21 days before their second admission suggests that the risk of nosocomial infection from the EMC Kailahun was not very high.

In this study it was not possible to comprehensively evaluate the initial triage step, i.e. the decision to admit a patient or not. For this, clinical, epidemiological and laboratory information of patients turned away at triage would have been necessary. Such information was not collected in Kailahun due to high workload.

Due to high work load and demanding working conditions during the overwhelming emergency situation when these data were collected, only the most operationally relevant information was entered into the electronic study database. Patient symptoms were not among them. Therefore, we could not identify key symptoms associated with having a positive laboratory result.

Only one laboratory test result at admission was recorded per patient. Patients with symptom onset less than 72 hours before admission who initially tested negative with a second test taken more than 72 hours after symptom onset which was positive had only had their second (positive) result recorded. Thus, it was not possible to investigate differences in ward allocation among this subgroup of patients.

In addition, no data on staff, logistics, finance and supply were available to estimate the burden of maintaining separate wards. This would have been necessary for a comprehensive evaluation of different EMC setups for patients awaiting laboratory confirmation.

\section{Conclusions}

This first assessment of the MSF EVD triage system into suspect and highly-suspect wards showed unconvincing results for the accurate classification of laboratoryconfirmed positive and negative admissions.

Instead, we recommend accommodating patients in single compartments pending laboratory confirmation whenever possible. Wherever this is not possible, a simplified separation into liquid and non-liquid producing patients should be considered and evaluated concurrently. At the same time, it is paramount to further improve the initial triage step on whether or not to admit a patient in the first place.

What is ultimately needed is a reliable, accurate, robust, mobile, affordable and easy to use point-ofcare test with high throughput capacity and quick turnaround time [34]. First field validations of proteinbased rapid tests showed promising results $[35,36]$, and other innovations such as GeneXpert for EBOV diagnostics and capillary blood testing indicate progress is being made, although much work still needs to be done to improve triage of EVD patients [37-39]. Further development of such devices should be encouraged and prioritised.

Acknowledgements

To our MSF colleagues who died during the Ebola outbreak in West Africa.

Conflict of interest

None declared.

Authors' contributions

Florian Vogt conceptualised and designed this research, led the analysis and interpretation of data, and wrote the first draft of the manuscript. Florian Vogt, Gabriel Fitzpatrick, Gabriela Patten and Kathryn Stinson were involved in the data collection. Gabriel Fitzpatrick, Gabriela Patten, Rafael van den Bergh, Luigi Pandolfi, James Squire, Tom Decroo, Hilde Declerck and Michel Van Herp contributed to the interpretation of data. All co-authors revised the draft manuscript critically for important intellectual content. All authors approved the final version of the manuscript.

\section{References}

1. Farrar JJ, Piot P. The Ebola emergency--immediate action, ongoing strategy.N Engl J Med. 2014;371(16):1545-6. DOI: 10.1056/NEJMe1411471 PMID: 25244185 
2. World Health Organization (WHO). Ebola virus disease in Guinea. Geneva: WHO; 23 March 2014. Available from: http:// www.afro.who.int/en/clusters-a-programmes/dpc/epidemica-pandemic-alert-and-response/outbreak-news/4063-ebolahemorrhagic-fever-in-guinea.html

3. Weyer J, Blumberg LH, Paweska JT. Ebola virus disease in West Africa - an unprecedented outbreak.S Afr Med J. 2014;104(8):555-6. DOI: 10.7196/samj.8672 PMID: 25213844

4. World Health Organization (WHO). Statement on the 1st meeting of the IHR Emergency Committee on the 2014 Ebola outbreak in West Africa. Geneva: WHO; 8 Augus 2014. Available from: http://who.int/mediacentre/news/ statements/2014/ebola-20140808/en/

5. Médecins Sans Frontières. Sierra Leone: Ebola cases expected to increase; 11 July 2014. Available from: http://www.msf.org. uk/article/sierra-leone-ebola-cases-expected-increase

6. Dowell SF, Mukunu R, Ksiazek TG, Khan AS, Rollin PE, Peters CJ. Transmission of Ebola hemorrhagic fever: a study of risk factors in family members, Kikwit, Democratic Republic of the Congo, 1995. Commission de Lutte contre les Epidémies à Kikwit.J Infect Dis. 1999;179(s1) Suppl 1;S87-91. DOI: 10.1086/514284 PMID: 9988169

7. Feldmann H, Geisbert TW. Ebola haemorrhagic fever.Lancet. 2011;377(9768):849-62. DOI: 10.1016/S0140-6736(10)60667-8 PMID: 21084112

8. Peters CJ, LeDuc JW. An introduction to Ebola: the virus and the disease.J Infect Dis. 1999;179(s1) Suppl 1;ix-xvi. DOI: 10.1086/514322 PMID: 9988154

9. Ksiazek TG, Rollin PE, Williams AJ, Bressler DS, Martin ML, Swanepoel R, et al. Clinical virology of Ebola hemorrhagic fever (EHF): virus, virus antigen, and IgG and IgM antibody findings among EHF patients in Kikwit, Democratic Republic of the Congo, 1995. J Infect Dis. 1999;179(s1) Suppl 1;S177-87. DOI: $10.1086 / 514321$ PMID: 9988182

10. Legrand J, Grais RF, Boelle PY, Valleron AJ, Flahault A. Understanding the dynamics of Ebola epidemics.Epidemiol Infect. 2007;135(4):610-21. DOI: 10.1017/So950268806007217 PMID: 16999875

11. Chowell G, Hengartner NW, Castillo-Chavez C, Fenimore PW, Hyman IM. The basic reproductive number of Ebola and the effects of public health measures: the cases of Congo and Uganda.J Theor Biol. 2004;229(1):119-26. DOI: 10.1016/j. jtbi.2004.03.006 PMID: 15178190

12. Towner JS, Sealy TK, Ksiazek TG, Nichol ST. High-throughput molecular detection of hemorrhagic fever virus threats with applications for outbreak settings.J Infect Dis. 2007;196(s2) Suppl 2;S205-12. DOI: 10.1086/520601 PMID: 17940951

13. Borchert M, Mutyaba I, Van Kerkhove MD, Lutwama J, Luwaga $\mathrm{H}$, Bisoborwa $\mathrm{G}$, et al. Ebola haemorrhagic fever outbreak in Masindi District, Uganda: outbreak description and lessons learned. BMC Infect Dis. 2011;11(1):357. DOI: 10.1186/14712334-11-357 PMID: 22204600

14. Roddy P, Colebunders R, Jeffs B, Palma PP, Van Herp M, Borchert M. Filovirus hemorrhagic fever outbreak case management: a review of current and future treatment options.J Infect Dis. 2011;204(Suppl 3):S791-5. DOI: 10.1093/ infdis/jir297 PMID: 21987752

15. World Health Organization (WHO). Case definition recommendations for Ebola or Marburg Virus Diseases. Geneva: WHO; 9 August 2014. Available from: http://www.who. int/csr/resources/publications/ebola/ebola-case-definitioncontact-en.pdf?ua=1

16. European Centre for Disease Prevention and Control (ECDC). Ebola virus disease case definition for reporting in EU. Stockholm: ECDC. [Accessed 16 Dec 2015]. Available from: http://ecdc.europa.eu/en/healthtopics/ebola_marburg_fevers/ EVDcasedefinition/Pages/default.aspx

17. Center for Disease Control and Prevention (CDC). Case Definition for Ebola Virus Disease (EVD). Atlanta: CDC; 16 November 2014. Available from: http://www.cdc.gov/vhf/ ebola/hcp/case-definition.html

18. Fitzpatrick G, Vogt F, Moi Gbabai O, Black B, Santantonio $M$, Folkesson $E$, et al. Describing readmissions to an Ebola case management centre (CMC), Sierra Leone, 2014. Euro Surveill. 2014;19(40):20924. DOI: 10.2807/1560-7917. ES2014.19.40.20924 PMID: 25323075

19. Fisher-Hoch SP. Lessons from nosocomial viral haemorrhagic fever outbreaks.Br Med Bull. 2005;73-74(1):123-37. DOI: 10.1093/bmb/Idho54 PMID: 16373655

20. World Health Organization (WHO). Interim Infection Prevention and Control Guidance for Care of Patients with Suspected or Confirmed Filovirus Haemorrhagic Fever in Health-Care Settings, with Focus on Ebola. Geneva: WHO; December 2014. Available from: http://apps.who.int/iris/ bitstream/10665/130596/1/WHO HIS SDS 2014.4 eng. pdf?ua $=1 \& u a=1 \& u a=1$
21. Towner JS, Rollin PE, Bausch DG, Sanchez A, Crary SM, Vincent M, et al. Rapid diagnosis of Ebola hemorrhagic fever by reverse transcription-PCR in an outbreak setting and assessment of patient viral load as a predictor of outcome. J Virol. 2004;78(8):4330-41. DOI: 10.1128/JVI.78.8.43304341.2004 PMID: 15047846

22. Center for Disease Control and Prevention (CDC). Guidance for Collection, Transport, and Submission of Specimens for Ebola Virus Testing in the United States. Atlanta: CDC; 30 January 2015. Available from: http://www.cdc.gov/vhf/ebola/pdf/ ebola-lab-guidance.pdf

23. Drazen JM, Kanapathipillai R, Campion EW, Rubin EJ, Hammer SM, Morrissey S, et al. Ebola and quarantine. N Engl J Med. 2014;371(21):2029-30. DOI: 10.1056/NEJMe1413139 PMID: 25347231

24. Sterk E. Filovirus Haemorrhagic Fever Guideline. Médecins Sans Frontières; 2008. Available from: www.medbox.org/ filovirus-haemorrhagic-fever-guideline/download.pdf

25. Statistics Sierra Leone. 2004 Population And Housing Census - Final Results; 2004. Available from: http://www.sierra-leone. org/Census/ssl_final_results.pdf

26. Gire SK, Goba A, Andersen KG, Sealfon RS, Park DJ, Kanneh $\mathrm{L}$, et al. Genomic surveillance elucidates Ebola virus origin and transmission during the 2014 outbreak. Science. 2014;345(6202):1369-72. DOI: 10.1126/science.1259657 PMID: 25214632

27. Washington Post. The birthplace of an outbreak; 28 August 2014. Available from: http://www.washingtonpost.com/sf/ style/2014/08/28/ebola-outbreak/

28. Wolz A. Face to face with Ebola--an emergency care center in Sierra Leone.N Engl J Med. 2014;371(12):1081-3. DOI: 10.1056/ NEJMp1410179 PMID: 25162580

29. de La Vega MA, Caleo G, Audet J, Qiu X, Kozak RA, Brooks J, et al. Ebola viral load at diagnosis associates with patient outcome and outbreak evolution. J Clin Invest. 2015;125(12):4421-8. DOI: 10.1172/JCI83162 PMID: 26551677

30. Altman DG, Bland JM. Statistics Notes: Diagnostic tests 2: Predictive values.BMJ. 1994;309(6947):102. DOI: 10.1136/ bmj.309.6947.102 PMID: 8038641

31. Bah El, Lamah MC, Fletcher T, Jacob ST, Brett-Major DM, Sal $A A$, et al. Clinical presentation of patients with Ebola virus disease in Conakry, Guinea. N Engl J Med. 2015;372(1):40-7. DOI: 10.1056/NEJMoa1411249 PMID: 25372658

32. Centers for Disease Control and Prevention (CDC), Nyenswah T, Fahnbulleh M, Massaquoi M, Nagbe T, Bawo L, Falla JD, et al. . Ebola epidemic--Liberia, March-October 2014.MMWR Morb Mortal Wkly Rep. 2014;63(46):1082-6.PMID: 25412068

33. Kelly JD. Make diagnostic centres a priority for Ebola crisis. Nature. 2014;513(7517):145. DOI: 10.1038/513145a PMID: 25209763

34. World Health Organization (WHO). Urgently needed: rapid, sensitive, safe and simple Ebola diagnostic tests. Geneva: WHO; 18 November 2014. Available from: http://www.who.int/ mediacentre/news/ebola/18-november-2014-diagnostics/en/

35. Broadhurst MJ, Kelly JD, Miller A, Semper A, Bailey D, Groppelli $E$, et al. ReEBOV Antigen Rapid Test kit for point-of-care and laboratory-based testing for Ebola virus disease: a field validation study. Lancet. 2015;386(9996):867-74. DOI: 10.1016/ So140-6736(15)61042-X PMID: 26119838

36. World Health Organization (WHO). Emergency Use Assessment and Listing for Ebola Virus Disease IVDs - Product: ReEBOVTM Antigen Rapid Test Kit EUAL. Geneva: WHO; June 2015. Available from: http://www.who.int/diagnostics_laboratory/ procurement/150219_reebov_antigen_rapid_test_public_ report.pdf?ua $=1$

37. Trust W. New 15-minute test for Ebola to be trialled in Guinea; 28 November 2014. Available from: http://www.wellcome. ac.uk/News/Media-office/Press-releases/2014/WTP058046. htm

38. World Health Organization. Emergency Use Assessment and Listing for EVD IVDs - Product: Xpert巴 Ebola Assay; May 2015. Available from: http://www.who.int/medicines/ebola-treatmen t/150508FinalPublicReportExpertEbola_Cepheid.pdf

39. Strecker T, Palyi B, Ellerbrok H, Jonckheere S, de Clerck H, Bore JA, et al. Field Evaluation of Capillary Blood Samples as a Collection Specimen for the Rapid Diagnosis of Ebola Virus Infection During an Outbreak Emergency. Clin Infect Dis. 2015;61(5):669-75. DOI: 10.1093/cid/civ397 PMID: 25991465 